\title{
Tranexamic acid reduces intraoperative occult blood loss and tourniquet time in obese knee osteoarthritis patients undergoing total knee arthroplasty: a prospective cohort study
}

This article was published in the following Dove Press journal:

Therapeutics and Clinical Risk Management

\author{
Yutong Mengl,* \\ Zhirui $\mathrm{Li}^{1,2, *}$ \\ Ke Gong' \\ Xiao $\mathrm{An}^{2}$ \\ Jiyuan Dong' \\ Peifu Tang' \\ 'Department of Orthopedics, Chinese \\ PLA General Hospital, Beijing, China; \\ ${ }^{2}$ Department of Orthopedics, Chinese \\ PLA General Hospital Hainan Branch, \\ Sanya, China \\ *These authors contributed equally \\ to this work
}

Correspondence: Peifu Tang; Jiyuan Dong Department of Orthopedics, Chinese PLA General Hospital, \#28 Fuxing Road, Haidian District, Beijing 100853, China

Tel +86 1068212342

+861066938401

Email pftang30I@I63.com; dongjiyuan8I30I@I63.com
Purpose: Obesity can result in increased blood loss, which is correlated with poor prognosis in total knee arthroplasty (TKA). Clinical application of tranexamic acid is effective in reducing blood loss in TKA. However, most previous studies focused on the effect of tranexamic acid in the whole population, neglecting patients with specific health conditions, such as obesity. We hypothesized that tranexamic acid would reduce blood loss to a greater extent in obese patients than in those of normal weight.

Patients and methods: A total of 304 patients with knee osteoarthritis treated with TKA from October 2013 to March 2015 were separated into tranexamic, non-tranexamic, obese, and non-obese groups. The demographic characteristics, surgical indices, and hematological indices were all recorded. We first investigated the ability of intravenous tranexamic acid to reduce intraoperative blood loss in knee osteoarthritis patients undergoing unilateral TKA. Second, we performed subgroup analysis to compare the effects of tranexamic acid between obese and non-obese patients separately.

Results: Of the 304 patients, $146(52.0 \%)$ received tranexamic acid and 130 (42.8\%) were obese. In the analysis of the whole group, both the actual and occult blood loss volume were lower in the tranexamic acid group (both $P<0.05$ ). Tourniquet time was shorter in the tranexamic acid group $(P<0.05)$. In subgroup analysis, tranexamic acid was shown to reduce theoretical and actual blood loss in both the obese and non-obese groups $(P<0.05)$. Tranexamic acid reduced occult blood loss and tourniquet time in the obese group $(P<0.05)$, while no such effects were observed in the non-obese group $(P>0.05)$.

Conclusion: Tranexamic acid can reduce occult blood loss and tourniquet time in obese patients to a greater extent than in patients of normal weight. Therefore, obese knee osteoarthritis patients undergoing TKA can benefit more from tranexamic acid.

Keywords: obese, knee osteoarthritis, total knee arthroplasty, blood conservation, tranexamic acid

\section{Introduction}

Total knee arthroplasty (TKA) is the optimal surgical option for severe knee osteoarthritis, and is now a well-established surgical technology. The demand for primary TKA is expected to increase to 3.48 million per year by 2030 in the USA. ${ }^{1}$ Through TKA, joint deformity correction, pain relief, walking function restoration, and improved quality of life can all be achieved. However, although TKA has many advantages, there are still some drawbacks. 
Previous studies showed that TKA is likely to cause a large amount of perioperative blood loss. ${ }^{2,3}$ This will not only increase the cost of surgery and risk of adverse events but also the probability of periprosthetic infection and even poorquality extremity function. ${ }^{4}$ Obesity aggravates this situation and can give rise to greater blood loss, which is correlated with a poor prognosis in surgical patients..$^{5-7}$ Therefore, the importance of blood conservation in obese patients with TKA surgery should not be underestimated.

Clinical application of tranexamic acid to reduce bleeding can be traced back to the 1970 s, with it initially being used mainly in cardiovascular surgery, and then gradually being applied in trauma and gastrointestinal hemorrhage surgery. ${ }^{8-10}$ The application of tranexamic acid in TKA surgery has become increasingly common in recent years. Previous studies have indicated the effectiveness of tranexamic acid for reducing visible and occult blood loss in TKA. ${ }^{11-15}$ However, most of these studies examined the effects of tranexamic acid on the general population. Only a few focused on patients with specific health states, such as obesity. ${ }^{16,17}$

Here, we hypothesized that tranexamic acid may reduce blood loss to a greater extent in obese patients (body mass index $[\mathrm{BMI}] \geq 30 \mathrm{~kg} / \mathrm{m}^{2}$ ) compared with those of normal weight (BMI $<30 \mathrm{~kg} / \mathrm{m}^{2}$ ). After investigating the ability of intravenous tranexamic acid to reduce intraoperative blood loss in knee osteoarthritis patients undergoing unilateral TKA, we performed a subgroup analysis to separately compare the effects of tranexamic acid in obese and non-obese patients. This study provides a more in-depth understanding of the characteristics of tranexamic acid for clinical reference.

\section{Patients and methods}

\section{Patient selection}

This prospective, observational cohort study was performed in accordance with the 1964 Declaration of Helsinki and was approved by the Medical Ethics Committee of Chinese PLA General Hospital, Beijing, China. From October 1, 2013 to March 31, 2015, four senior surgeons at the Department of Orthopedics of Chinese PLA General Hospital prospectively enrolled 427 consecutive knee osteoarthritis patients treated with TKA into this study. Knee osteoarthritis was diagnosed based on clinical symptoms and radiographic test. The Kellgren-Lawrence grading scale was used for grading knee osteoarthritis. ${ }^{18}$ The choice of treatment is based on clinical symptoms including pain and decreased function. If the pain or decreased function seriously affects daily life and conservative management is ineffective, TKA is recommended. The Kellgren-Lawrence scale is usually grade III or above. All four surgeons have experience with TKA surgery.
Patients were included if they underwent TKA for treatment of knee osteoarthritis. Forty patients were excluded based on the following exclusion criteria: 1 ) age $<40$ or $>90$ years; 2) pre-existing hemorrhagic or coagulation disorders; and 3) refusal to participate in the study. After primary screening, 387 participants fulfilled the basic criteria, of whom 83 were excluded because they were undergoing revision arthroplasty or staged or simultaneous bilateral TKA. Thus, 304 participants were finally enrolled in the study (Figure 1). All patients provided written informed consent.

\section{Treatment assignment}

After admission, all participants underwent a detailed preoperative examination followed by TKA. The surgical protocol was designed by four senior surgeons at the Department of Orthopedics of Chinese PLA General Hospital. Before surgery, 146 participants received intravenous tranexamic acid at a dose of $20 \mathrm{mg} / \mathrm{kg}$ body weight $(10 \mathrm{mg} / \mathrm{kg} 10 \mathrm{~min}$ before making initial incision and another $10 \mathrm{mg} / \mathrm{kg} 10 \mathrm{~min}$ before tourniquet release), while the others were not treated with tranexamic acid; ie, the participants were divided into tranexamic acid and non-tranexamic acid groups. The tourniquet was inflated to $300-330 \mathrm{mmHg}$ before making initial incision and released following wound closure. The pressure was set according to the patient's blood pressure.

\section{Data collection}

After admission, participants' demographic characteristics, medical comorbidities, and previous medical history data were collected. Surgeons also recorded preoperative parameters, such as diagnoses, physical examination, and radiographic results. In addition, surgical details such as intraoperative blood loss volume, intraoperative red blood cell transfusion volume, operation time, and tourniquet use were also recorded. Postoperative local swelling and drainage volume were recorded. The postoperative local swelling was defined as swelling around the incision area after surgery.

The complete blood cell count results at $1 \mathrm{~d}$ preoperatively and $1 \mathrm{~d}$ postoperatively were recorded using a hematology analyzer (XE-2100; Sysmex Corporation, Kobe, Japan). With regard to hematological parameters, total blood volume, theoretical blood loss volume, intraoperative blood loss volume, intraoperative red blood cell transfusion volume, actual blood loss volume, and occult blood loss volume were also calculated and recorded.

Total blood volume was calculated based on the equation of Nadler et al: ${ }^{19}$ for male patients, total blood volume $(\mathrm{mL})=366.9 \times$ height $^{3}\left(\mathrm{~m}^{3}\right)+32.19 \times$ weight $(\mathrm{kg})+604.1$; for female patients, total blood volume $(\mathrm{mL})=356.1 \times$ height $^{3}$ 


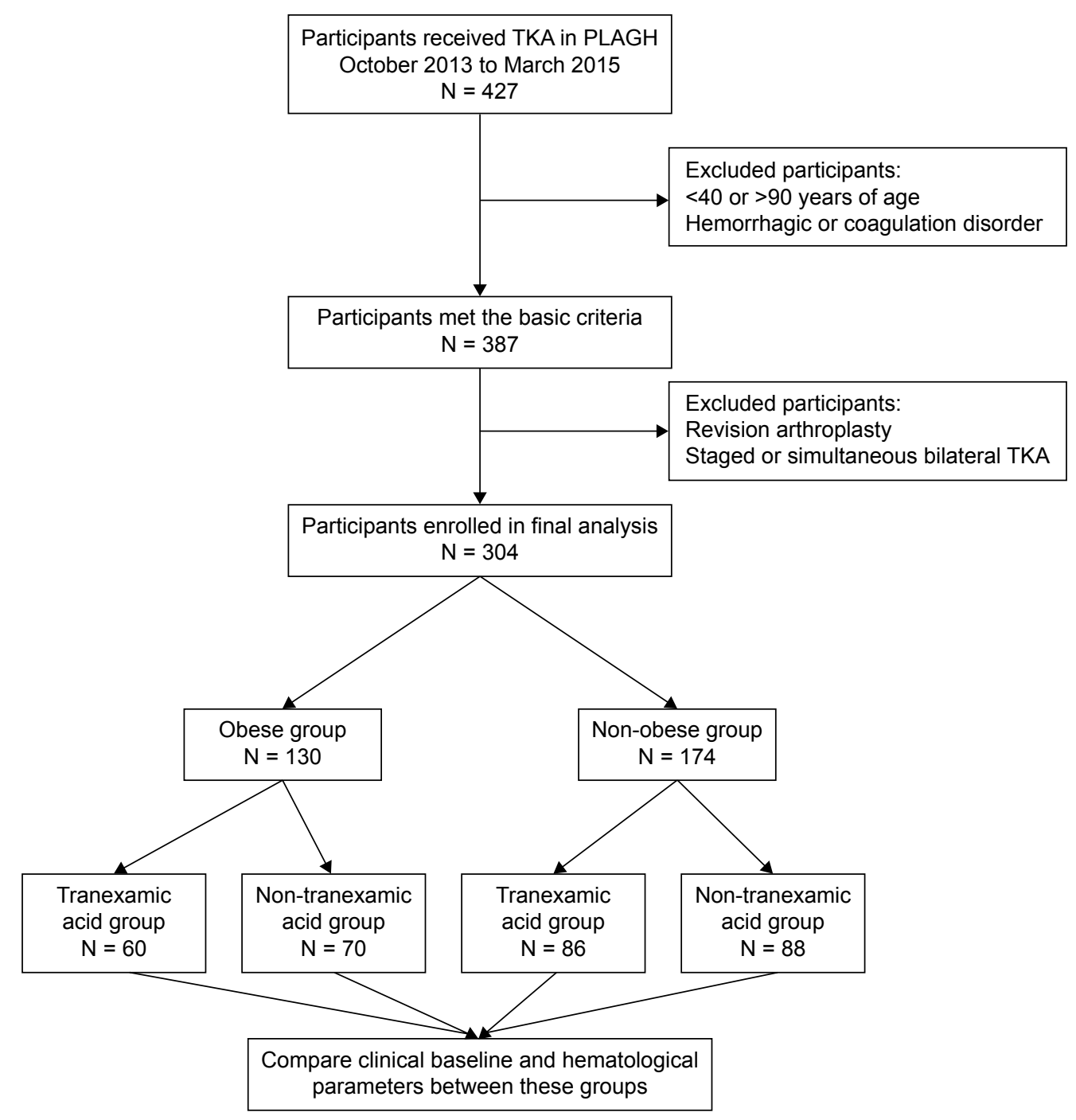

Figure I Study cohort and design.

Abbreviations: TKA, total knee arthroplasty; PLAGH, Chinese PLA General Hospital.

$\left(\mathrm{m}^{3}\right)+33.08 \times$ weight $(\mathrm{kg})+183.3$. Theoretical blood loss volume was calculated by the equation of Gross: ${ }^{20}$ theoretical blood loss volume $(\mathrm{mL})=$ total blood volume $(\mathrm{mL}) \times$ (preoperative $1 \mathrm{~d}$ hematocrit - postoperative $1 \mathrm{~d}$ hematocrit). As the Gross equation does not take into account red blood cell transfusion, we calculated the actual blood loss volume using the following equation: actual blood loss volume $(\mathrm{mL})=$ theoretical blood loss volume $(\mathrm{mL})+$ red blood cell transfusion volume. Occult blood loss volume $(\mathrm{mL})=$ actual blood loss volume $(\mathrm{mL})-$ intraoperative blood loss volume $(\mathrm{mL})$.

\section{Statistical analysis}

All statistical analyses were performed using SPSS software (IBM Corporation, Armonk, NY, USA). For the measured variables, normality of distribution was evaluated by the Shapiro-Wilk test. Normally distributed data are presented as means \pm SD. Differences between groups were compared using Student's $t$-test. For abnormally distributed variables or those with heterogeneity of variance, the data are presented as the median and interquartile range (Q1, Q3). Differences between groups were compared by the Mann-Whitney $U$-test. For categorical data, the number of patients in each category was recorded. Pearson's chi-squared test or Fisher's exact test was used for comparison between groups where appropriate. In all analyses, $P<0.05$ was taken to indicate statistical significance.

\section{Results}

\section{Study population}

Of the 304 subjects included in the study, 250 (82.8\%) were females and $54(17.8 \%)$ were males. The average age was 66.06 years (range: $44-87$ years). Hypertension was the most common complication, with an incidence of 59.6\% 
Table I Clinical characteristics of study population

\begin{tabular}{ll}
\hline Items & Total, N = 304 \\
\hline Gender & \\
$\quad$ Male & $54(17.8 \%)$ \\
$\quad$ Female & $250(82.2 \%)$ \\
Age (years) & $66.06 \pm 7.36$ \\
Hypertension & $173(56.9 \%)$ \\
Diabetes mellitus & $45(14.8 \%)$ \\
Cardiovascular diseases & $46(15.1 \%)$ \\
Cerebral infarction & $25(8.2 \%)$ \\
Anticoagulation therapy & \\
Rivaroxaban & $181(59.5 \%)$ \\
LMWH & $123(40.5 \%)$ \\
\hline
\end{tabular}

Abbreviation: LMWH, low-molecular-weight heparin.

(173 cases). Other major preoperative complications were cardiovascular diseases, diabetes mellitus, and cerebral infarction. All participants received anticoagulation therapy perioperatively. Among them, 181 (59.5\%) received oral rivaroxaban, while 123 (40.5\%) received hypodermic injection of low-molecular-weight heparin (Table 1). A total of $146(52.0 \%)$ patients received tranexamic acid, and $130(42.8 \%)$ patients were obese.

\section{Comparison of baseline characteristics and perioperative parameters between tranexamic acid and non-tranexamic acid groups}

The baseline characteristics were compared between the tranexamic acid group and non-tranexamic acid group. As shown in Table 2, there were no statistically significant differences in gender, age, pre-existing conditions, or perioperative anticoagulation therapy between the two groups. Hematological parameters were compared between the tranexamic acid group and non-tranexamic acid group. As shown in Table 3, there were no differences in hemoglobin $(\mathrm{Hb})$ or hematocrit levels between the two groups at $1 \mathrm{~d}$ before the operation. However, significant differences in $\mathrm{Hb}$ and hematocrit levels were observed between the two groups on postoperative day $1 . \mathrm{Hb}$ and hematocrit levels were all higher in the tranexamic acid group than the non-tranexamic acid group $(P<0.05)$. There was no difference in total blood volume between the two groups $(P>0.05)$. Theoretical blood loss volume was lower in the tranexamic acid group than the non-tranexamic acid group $(P<0.05)$. There were no differences in intraoperative blood loss volume or intraoperative red blood cell transfusion volume between the two groups $(P>0.05)$. The actual blood loss volume and occult blood loss volume were significantly lower in the tranexamic acid group than the non-tranexamic acid group $(P<0.05)$. In addition, the duration of tourniquet application was shorter in the tranexamic acid group than the non-tranexamic acid group $(P<0.05)$. However, there were no differences in operation time, postoperative drainage volume, or postoperative local swelling between the two groups $(P>0.05)$.

\section{Subgroup analysis between obese and non-obese groups}

As shown in Table 4, only hypertension in the obese group was significantly different between tranexamic acid and non-tranexamic acid groups. As shown in Table 5, in the non-obese group, $\mathrm{Hb}$ and hematocrit levels on day 1 after surgery were significantly different between the tranexamic

Table 2 Comparison of clinical baseline characteristics between tranexamic acid group and non-tranexamic acid group

\begin{tabular}{|c|c|c|c|c|}
\hline & $\begin{array}{l}\text { Tranexamic } \\
\text { acid group } \\
N=146 \\
(52.0 \%)\end{array}$ & $\begin{array}{l}\text { Non-tranexamic } \\
\text { acid group } \\
\mathbf{N}=158 \\
(48.0 \%)\end{array}$ & Statistics* & $P$-value \\
\hline Gender & & & 0.338 & 0.561 \\
\hline Male & $24(16.4 \%)$ & $30(19.0 \%)$ & & \\
\hline Female & $122(83.6 \%)$ & $128(81.0 \%)$ & & \\
\hline Age (years) & $66.44 \pm 6.84$ & $65.70 \pm 7.82$ & 0.870 & 0.385 \\
\hline Hypertension & $90(61.6 \%)$ & $83(52.5 \%)$ & 2.569 & 0.109 \\
\hline Diabetes mellitus & $23(\mid 5.8 \%)$ & $22(13.9 \%)$ & 0.201 & 0.654 \\
\hline Cardiovascular diseases & 17 (II.6\%) & $29(18.4 \%)$ & $2.66 \mathrm{I}$ & 0.103 \\
\hline Cerebral infarction & 15 (10.3\%) & $10(6.3 \%)$ & 1.565 & 0.211 \\
\hline Anticoagulation therapy & & & 0.000 & 0.986 \\
\hline Rivaroxaban & 87 (59.6\%) & $94(59.5 \%)$ & & \\
\hline LMWH & 59 (40.4\%) & $64(40.5 \%)$ & & \\
\hline
\end{tabular}

Notes: *For normally distributed data, differences between groups were compared by Student's $t$-test and shown as $T$-statistics. For categorical data, differences between groups were compared by Pearson's chi-squared test and shown as $\chi^{2}$-statistics.

Abbreviation: $\mathrm{LMWH}$, low-molecular-weight heparin. 
Table 3 Comparison of perioperative parameters between tranexamic acid group and non-tranexamic acid group

\begin{tabular}{|c|c|c|c|c|}
\hline & \multirow{2}{*}{$\begin{array}{l}\text { Tranexamic acid group } \\
N=146(52.0 \%)\end{array}$} & \multirow{2}{*}{$\begin{array}{l}\text { Non-tranexamic acid group } \\
N=\text { I } 58(48.0 \%)\end{array}$} & \multirow[t]{2}{*}{ Statistics* } & \multirow[t]{2}{*}{$P$-value } \\
\hline & & & & \\
\hline Preoperative I d Hb (g/L) & $131.96 \pm 11.89$ & $|3| .4 \mid \pm 13.20$ & 0.383 & 0.702 \\
\hline Preoperative I d HCT (\%) & $39.50 \pm 3.26$ & $39.36 \pm 3.62$ & 0.352 & 0.725 \\
\hline Postoperative I d Hb (g/L) & $|27.4| \pm 13.59$ & $120.73 \pm 13.86$ & 4.235 & 0.000 \\
\hline Postoperative I d HCT (\%) & $37.44 \pm 3.68$ & $35.61 \pm 3.84$ & 4.235 & 0.000 \\
\hline Total preoperative blood volume $(\mathrm{mL})$ & $3,901.77(3,667.16,4,255.21)$ & $3,986.34(3,614.81,4,405.84)$ & -0.398 & 0.690 \\
\hline Theoretical blood loss volume (mL) & $85.53(-9.62,156.49)$ & $161.23(36.06,243.57)$ & -4.579 & 0.000 \\
\hline Intraoperative blood loss volume (mL) & $203.63 \pm 74.28$ & $210.13 \pm 75.87$ & -0.753 & 0.452 \\
\hline Intraoperative red cell transfusion volume $(\mathrm{mL})$ & $415.58 \pm 118.87$ & $403.01 \pm 130.17$ & 0.877 & 0.381 \\
\hline Actual blood loss volume $(\mathrm{mL})$ & $494.29(401.39,593.98)$ & $553.98(440.33,662.33)$ & -3.292 & 0.001 \\
\hline Occult blood loss volume (mL) & $294.97 \pm 151.18$ & $348.39 \pm 173.04$ & -2.856 & 0.005 \\
\hline Postoperative drainage volume $(\mathrm{mL})$ & $54.44 \pm 44.03$ & $62.61 \pm 59.93$ & -1.346 & 0.179 \\
\hline Operation time $(\mathrm{min})$ & $110.00(95.00,121.00)$ & III.00 (98.50, I28.00) & -1.212 & 0.225 \\
\hline Tourniquet time (min) & $56.50(46.00,63.25)$ & $61.00(51.25,71.00)$ & -3.549 & 0.000 \\
\hline Postoperative local swelling & $7(4.8 \%)$ & $9(5.7 \%)$ & 0.124 & 0.725 \\
\hline
\end{tabular}

Notes: *For normally distributed data, differences between groups were compared by Student's $t$-test and shown as T-statistics. For abnormally distributed variables or those with heterogeneity of variance, differences between groups were compared by Mann-Whitney U-test and shown as Z-statistics. For categorical data, differences between groups were compared by Pearson's chi-squared test and shown as $\chi^{2}$-statistics.

Abbreviations: $\mathrm{Hb}$, hemoglobin; $\mathrm{HCT}$, hematocrit.

acid group and non-tranexamic acid group. Also, the same effect was observed on the first day postoperatively in the obese group $(P<0.05)$. In addition, tranexamic reduced theoretical blood loss and actual blood loss in both the obese and non-obese groups $(P<0.05)$. Interestingly, we found that tranexamic acid reduced occult blood loss and tourniquet time in the obese group $(P<0.05)$, while no such effects were observed in the non-obese group $(P>0.05)$.

\section{Discussion}

Anemia can lead to a prolonged hospital stay, delayed rehabilitation, and poor tolerance in patients undergoing elective total hip arthroplasty or TKA. Therefore, the importance of blood conservation should not be underestimated. ${ }^{4}$ There are a number of ways to reduce perioperative blood loss, including preoperative blood reserves, controlled hypotension, perioperative use of erythropoietin, and intraoperative use of a tourniquet. However, these techniques are not without their own drawbacks. For example, hypotension cannot be controlled easily. If sudden surgical bleeding occurs, hypotension can make the patient more prone to cardiac arrest. In addition, the ischemic threshold of individual organs cannot be estimated, and dangerous or even life-threatening complications, such as neurological defects or myocardial

Table 4 Subgroup analysis of baseline characteristics between obese and non-obese groups

\begin{tabular}{|c|c|c|c|c|c|c|c|c|}
\hline & \multicolumn{4}{|l|}{$\begin{array}{l}\text { Obese group } \\
N=130\end{array}$} & \multicolumn{4}{|c|}{$\begin{array}{l}\text { Non-obese group } \\
N=174\end{array}$} \\
\hline & $\begin{array}{l}\text { Tranexamic } \\
\text { acid group } \\
N=60\end{array}$ & $\begin{array}{l}\text { Non-tranexamic } \\
\text { acid group } \\
\mathbf{N}=\mathbf{7 0}\end{array}$ & Statistics* & $P$-value & $\begin{array}{l}\text { Tranexamic } \\
\text { acid group } \\
\mathbf{N}=\mathbf{8 6}\end{array}$ & $\begin{array}{l}\text { Non-tranexamic } \\
\text { acid group } \\
\mathbf{N}=\mathbf{8 8}\end{array}$ & Statistics* & $P$-value \\
\hline Gender & & & 1.121 & 0.290 & & & 0.010 & 0.920 \\
\hline Male & $5(8.3 \%)$ & $10(14.3 \%)$ & & & $19(22.1 \%)$ & $20(22.7 \%)$ & & \\
\hline Female & 55 (9l.7\%) & $60(85.7 \%)$ & & & 67 (77.9\%) & $68(77.3 \%)$ & & \\
\hline Age (years) & $65.82 \pm 7.00$ & $64.80 \pm 7.80$ & 0.694 & 0.489 & $66.87 \pm 6.73$ & $66.42 \pm 7.81$ & 0.408 & 0.684 \\
\hline Hypertension & 47 (78.3\%) & 43 (6I.4\%) & 4.334 & 0.037 & $43(50.0 \%)$ & 40 (45.5\%) & 0.360 & 0.548 \\
\hline Diabetes mellitus & 13 (21.7\%) & $9(12.9 \%)$ & 1.783 & 0.182 & $10(11.6 \%)$ & 13 (I4.8\%) & 0.375 & 0.540 \\
\hline Cardiovascular diseases & $4(6.7 \%)$ & II (I5.7\%) & 2.591 & 0.107 & $13(15.1 \%)$ & I 8 (20.5\%) & 0.847 & 0.358 \\
\hline Cerebral infarction & $5(8.3 \%)$ & $4(5.7 \%)$ & 0.058 & 0.810 & $10(11.6 \%)$ & $6(6.8 \%)$ & 1.205 & 0.272 \\
\hline Anticoagulation therapy & & & 0.028 & 0.868 & & & 0.033 & 0.857 \\
\hline Rivaroxaban & $36(60.0 \%)$ & 43 (6I.4\%) & & & $5 \mathrm{I}(59.3 \%)$ & $5 \mathrm{I}(58.0 \%)$ & & \\
\hline LMWH & $24(40.0 \%)$ & 27 (38.6\%) & & & 35 (40.7\%) & 37 (42.0\%) & & \\
\hline
\end{tabular}

Notes: *For normally distributed data, differences between groups were compared by Student's $t$-test and shown as $T$-statistics. For categorical data, differences between groups were compared by Pearson's chi-squared test and shown as $\chi^{2}$-statistics. Abbreviation: LMWH, low-molecular-weight heparin. 


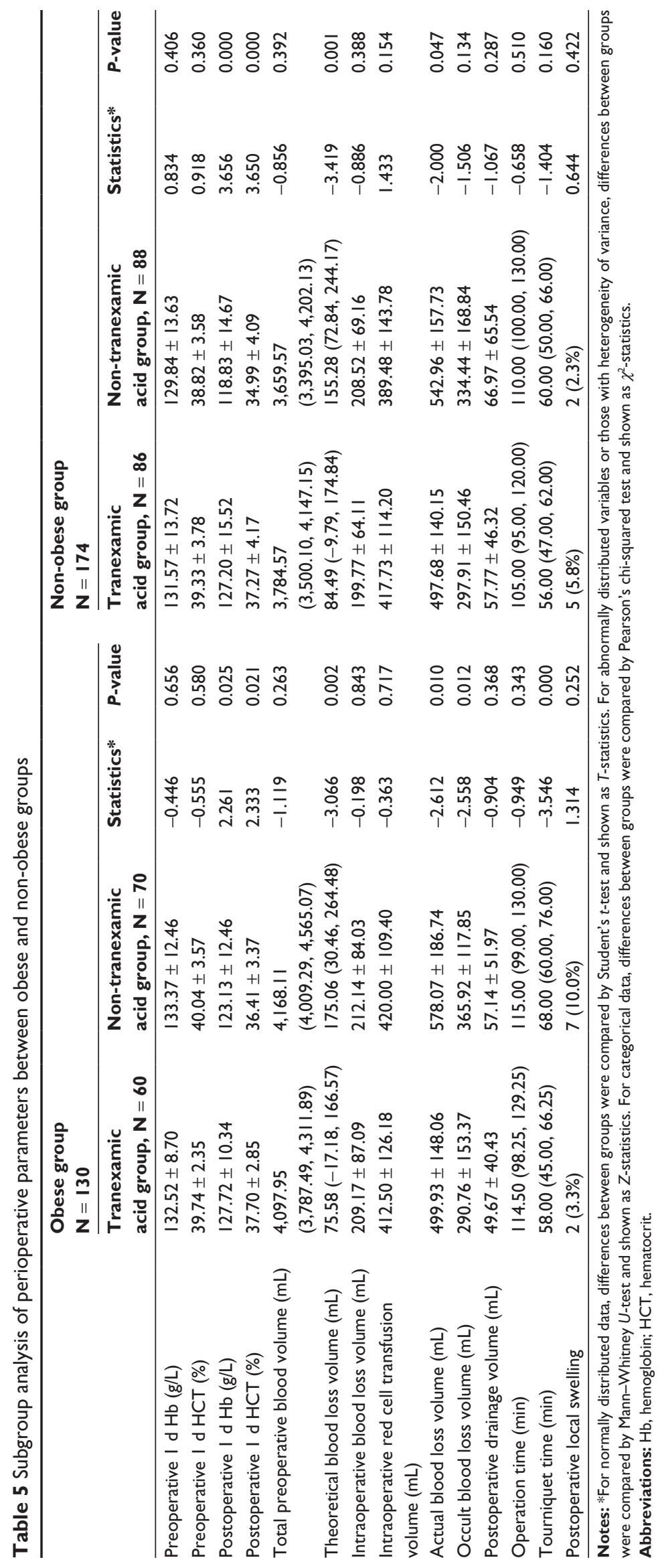


ischemia, may occur. ${ }^{21}$ Therefore, surgeons are seeking safer ways to reduce perioperative blood loss.

Consistent with previous studies, the results of the present study indicated that tranexamic acid is effective for reducing blood loss in knee osteoarthritis patients undergoing unilateral TKA. A previous meta-analysis by Yang et al showed that tranexamic acid was effective and safe for reducing blood loss in patients undergoing TKA. ${ }^{22}$ As with blood transfusion, Seol et al found that tranexamic acid is effective in reducing the red blood cell transfusion volume. In addition, tranexamic acid was reported to reduce the volume of blood transfusion from 1.28 to 0.76 units. ${ }^{23}$ Another meta-analysis indicated that blood loss and transfusion rates in primary TKA can be effectively reduced by the use of tranexamic acid. ${ }^{24}$ However, there were no significant differences in intraoperative red cell transfusion volume between the tranexamic acid group and non-tranexamic acid group in the present study.

Obese patients are more prone to have elevated levels of blood lipids, which promotes atherosclerosis. Considering the altered vascular structure and hemodynamics seen in obese patients, massive blood loss and prolonged tourniquet use intraoperatively can have serious consequences. This is correlated with a poor clinical prognosis in TKA patients. ${ }^{5-7}$ To investigate how to avoid this situation, various studies performed subgroup analysis to compare the effect of tranexamic acid between obese and non-obese patients. Meftah compared the effect of tranexamic acid on change in hematocrit and blood transfusion rate between normal weight and morbidly obese patients. They found the transfusion rate and drop in hematocrit were significantly less for morbidly obese patients who received tranexamic acid. ${ }^{16}$ Tuttle et al compared delta $\mathrm{Hb}$, postoperative $\mathrm{Hb}$, and transfusion rate between patients with $\mathrm{BMI}<30 \mathrm{~kg} / \mathrm{m}^{2}$ and $\mathrm{BMI} \geq 30 \mathrm{~kg} / \mathrm{m}^{2}$. They found patients with BMI $\geq 30 \mathrm{~kg} / \mathrm{m}^{2}$ had a significant difference in their delta $\mathrm{Hb}$, postoperative $\mathrm{Hb}$, and transfusion rate. ${ }^{17}$ However, they only compared hematological indexes such as hematocrit and $\mathrm{Hb}$, which cannot exclude the interference of external factors such as blood transfusion. To minimize such interference, we calculated and compared the actual blood loss volume based on previously proposed equations. ${ }^{19,20}$ Interestingly, we found differences in the effects of tranexamic acid between the two groups. First, tranexamic acid effectively reduced intraoperative occult blood loss in obese patients $(P=0.012)$. However, no such effect was observed in non-obese patients $(P=0.134)$. Second, tranexamic acid effectively reduced the intraoperative tourniquet time in obese patients $(P=0.000)$, while no such effect was seen in non-obese patients $(P=0.160)$. Additionally, for those patients who did not use tranexamic acid, the obese patients had significantly longer tourniquet time than the non-obese patients (median 68.00 vs $60.00, P=0.000$ ). For those patients who used tranexamic acid, the tourniquet time of obese patients reduced to the same level as the nonobese patients (median 58.00 vs $56.00, P=0.570$ ). These observations indicated that tranexamic acid can reduce occult blood loss and tourniquet time to a greater extent in obese patients than in non-obese patients. Thus, tranexamic acid can effectively solve the problem of blood loss control in obese patients.

In this study, there was a strong imbalance between males $(17.8 \%)$ and females $(82.8 \%)$. After reviewing the relevant papers, females have greater knee osteoarthritis prevalence $(67.4 \%)$ and a greater proportion of women have mobility limitations as well as hip and knee pain. The proportion of female patients with severe knee osteoarthritis who received TKA was even higher than $67.4 \% .{ }^{25}$ Our study is consistent with the results of this previous study. Additionally, we further analyzed the distribution differences of genders between obese/non-obese groups and tranexamic acid/nontranexamic acid groups (Table 4). We found no significant differences of genders between groups. Therefore, the minimum effect due to gender distribution on the result can be guaranteed. Obesity is a mixed disease state, which is usually accompanied by other metabolic syndromes, such as hypertension, diabetes mellitus, and cholesterol changes. We performed baseline analysis on possible comorbidities such as hypertension, diabetes mellitus, cardiovascular diseases, and cerebral infarction. From Table 2, we can see there were no statistical differences in comorbidities between the tranexamic acid group and non-tranexamic acid group. From Table 4, we can see only the obese group had a slight imbalance in hypertension. A further analysis showed an imbalance of hypertension distribution between obese and non-obese groups.

Tranexamic acid was administered intravenously at a dose of $20 \mathrm{mg} / \mathrm{kg}$ body weight $(10 \mathrm{mg} / \mathrm{kg} 10 \mathrm{~min}$ before making initial incision and another $10 \mathrm{mg} / \mathrm{kg} 10 \mathrm{~min}$ before tourniquet release) in the present study. There have been a number of studies examining the optimal dose and mode of administration of tranexamic acid. Some authors preferred intravenous administration of tranexamic acid, as in the present study, while others preferred oral or topical administration. Cankaya et al found that oral and topical tranexamic acid administration were safe, efficient, and economical methods for reducing blood loss and transfusion 
rates in patients undergoing TKA. ${ }^{14}$ However, most recent studies indicated that the effects of oral and intravenous administration of tranexamic acid were the same. ${ }^{12,13}$ A recent meta-analysis by Dai et al also found no difference between topical and intravenous tranexamic acid in terms of transfusion rate or total blood loss. ${ }^{11}$ As with the dose of tranexamic acid, $20 \mathrm{mg} / \mathrm{kg}$ body weight is consistent with the review of Melvin et al, indicating that an intravenous dose of $10-20 \mathrm{mg} / \mathrm{kg}$ tranexamic acid is reasonable for patients undergoing primary TKA. ${ }^{26}$ This dose was also consistent with other previous studies and proved to be valid to meet clinical requirement. ${ }^{27,28}$

Considering the previously mentioned results in this study, one possible mechanism of action of the drug is that tranexamic acid is an antifibrinolytic amino acid that can reversibly bind lysine receptor sites on plasminogen or plasmin. It further prevents binding of plasmin and fibrin, thus inhibiting plasmin proteolytic activity. ${ }^{29}$ On the other hand, in patients with metabolic syndrome as well as obesity, PAI-1 has been proven to be present at an increased level. ${ }^{30} \mathrm{PAI}-1$ functions as an inhibitor of tissue plasminogen activator. PAI-1 can prevent the conversion of plasminogen to plasmin. Under such circumstances, tranexamic acid and PAI-1 are two important inhibitors of fibrinolysis, and their synergism can modulate a greater antifibrinolysis effect. The effect of metabolic syndromes on tranexamic acid may be clarified by further animal experiments.

In this study, all operations were performed by four senior orthopedic surgeons, thus minimizing any effect of the different preferences and experience levels among surgeons. In addition, all data in this study were collected prospectively, and the surgeons and data analysts were blinded. However, this study had the limitations of being performed in a single center with a relatively small study population. Further multicenter randomized controlled trials in larger populations are required. Additionally, all the patients were treated with the same dose of tranexamic acid with no regard to gender, blood volume or other factors. Based on the result of this study, we are proposing that adjusting the dose according to gender and blood volume would be a potential research target. Further research is required.

\section{Conclusion}

In conclusion, tranexamic acid can reduce intraoperative blood loss and tourniquet time in TKA patients. However, subgroup analysis between obese and non-obese patients indicated that tranexamic acid can reduce occult blood loss and tourniquet time to a greater extent in obese patients than in those of normal weight. Therefore, obese knee osteoarthritis patients undergoing TKA can benefit more from tranexamic acid.

\section{Acknowledgments}

Partial work in this study was supported by medical big data research project of Chinese PLA General Hospital (2016MBD-006). We would like to thank all patients and staff who participated in this study. The authors would like to thank all the editors and the reviewers for their constructive comments that have significantly contributed to the improvement of our manuscript.

\section{Disclosure}

The authors report no conflicts of interest in this work.

\section{References}

1. Kurtz S, Ong K, Lau E, Mowat F, Halpern M. Projections of primary and revision hip and knee arthroplasty in the United States from 2005 to 2030. J Bone Joint Surg Am. 2007;89(4):780-785.

2. Frisch NB, Wessell NM, Charters MA, et al. Predictors and complications of blood transfusion in total hip and knee arthroplasty. J Arthroplasty. 2014;29(9 Suppl):189-192.

3. Park JH, Rasouli MR, Mortazavi SM, et al. Predictors of perioperative blood loss in total joint arthroplasty. J Bone Joint Surg Am. 2013; 95(19): 1777-1783

4. Carson JL, Duff A, Berlin JA, et al. Perioperative blood transfusion and postoperative mortality. JAMA. 1998;279(3):199-205.

5. Goldin AN, Alander DH. Effect of body mass index on early outcomes of minimally invasive degenerative lumbar surgery. J Surg Orthop Adv. 2015;24(1):12-17.

6. Dere D, Paker N, Soy Bugdayci D, Tekdos Demircioglu D. Effect of body mass index on functional recovery after total knee arthroplasty in ambulatory overweight or obese women with osteoarthritis. Acta Orthop Traumatol Turc. 2014;48(2):117-121.

7. Kerkhoffs GM, Servien E, Dunn W, et al. The influence of obesity on the complication rate and outcome of total knee arthroplasty: a metaanalysis and systematic literature review. J Bone Joint Surg Am. 2012; 94(20):1839-1844.

8. Weintraub M. Clinical trial of tranexamic acid. N Engl J Med. 1972; 287(21):1099.

9. Cormack F, Chakrabarti RR, Jouhar AJ, Fearnley GR. Tranexamic acid in upper gastrointestinal haemorrhage. Lancet. 1973;1(7814): 1207-1208.

10. CRASH-2 collaborators, Roberts I, Shakur H, et al. The importance of early treatment with tranexamic acid in bleeding trauma patients: an exploratory analysis of the CRASH-2 randomised controlled trial. Lancet. 2011;377(9771):1096-1101.

11. Dai WL, Zhou AG, Zhang H, Zhang J. Most effective regimen of tranexamic acid for reducing bleeding and transfusions in primary total knee arthroplasty: a meta-analysis of randomized controlled trials. J Knee Surg. Epub 2017 Sep 11.

12. Luo ZY, Wang HY, Wang D, et al. Oral vs intravenous vs topical tranexamic acid in primary hip arthroplasty: a prospective, randomized, double-blind, controlled study. J Arthroplasty. 2018;33(3):786-793.

13. Kayupov E, Fillingham YA, Okroj K, et al. Oral and intravenous tranexamic acid are equivalent at reducing blood loss following total hip arthroplasty: a randomized controlled trial. J Bone Joint Surg Am. 2017;99(5):373-378. 
14. Cankaya D, Dasar U, Satilmis AB, et al. The combined use of oral and topical tranexamic acid is a safe, efficient and low-cost method in reducing blood loss and transfusion rates in total knee arthroplasty. J Orthop Surg (Hong Kong). 2017;25(1):2309499016684725.

15. Kasparek MF, Faschingbauer M, Waldstein W, Boettner CS, Boettner F. Topical tranexamic acid is equivalent to targeted preoperative autologous blood donation in total hip arthroplasty. J Arthroplasty. 2017;32(4): 1176-1179.

16. Meftah M. Tranexamic acid in morbidly obese patients. Orthopaedic Proceedings. 2016;98-B(Supp 9):42-42.

17. Tuttle JR, Anazonwu W, Rubin LE. Subgroup analysis of topical tranexamic acid in total knee arthroplasty. Reconstructive Review. 2014; 4(2):37-41.

18. Kellgren JH, Lawrence JS. Radiological assessment of osteo-arthrosis. Ann Rheum Dis. 1957;16(4):494-502.

19. Nadler SB, Hidalgo JH, Bloch T. Prediction of blood volume in normal human adults. Surgery. 1962;51(2):224-232.

20. Gross JB. Estimating allowable blood loss: corrected for dilution. Anesthesiology. 1983;58(3):277-280.

21. Dutton RP. Controlled hypotension for spinal surgery. Eur Spine J. 2004;13 Suppl 1:S66-S71.

22. Yang ZG, Chen WP, Wu LD. Effectiveness and safety of tranexamic acid in reducing blood loss in total knee arthroplasty: a meta-analysis. J Bone Joint Surg Am. 2012;94(13):1153-1159.
23. Seol YJ, Seon JK, Lee SH, et al. Effect of tranexamic acid on blood loss and blood transfusion reduction after total knee arthroplasty. Knee Surg Relat Res. 2016;28(3):188-193.

24. Wang H, Shen B, Zeng Y. Blood loss and transfusion after topical tranexamic acid administration in primary total knee arthroplasty. Orthopedics. 2015;38(11):e1007-e1016.

25. Plotnikoff R, Karunamuni N, Lytvyak E, et al. Osteoarthritis prevalence and modifiable factors: a population study. BMC Public Health. 2015; $15: 1195$

26. Melvin JS, Stryker LS, Sierra RJ. Tranexamic acid in hip and knee arthroplasty. J Am Acad Orthop Surg. 2015;23(12):732-740.

27. MacGillivray RG, Tarabichi SB, Hawari MF, Raoof NT. Tranexamic acid to reduce blood loss after bilateral total knee arthroplasty: a prospective, randomized double blind study. J Arthroplasty. 2011;26(1): 24-28.

28. Tanaka N, Sakahashi H, Sato E, et al. Timing of the administration of tranexamic acid for maximum reduction in blood loss in arthroplasty of the knee. J Bone Joint Surg Br. 2001;83(5):702-705.

29. Alburaih A. Tranexamic acid (TXA) in trauma patients: barriers to use among trauma surgeons and emergency physicians. Emerg Med Int. 2017;2017:4235785.

30. Trayhurn P. Endocrine and signalling role of adipose tissue: new perspectives on fat. Acta Physiol Scand. 2005;184(4):285-293.
Therapeutics and Clinical Risk Management

\section{Publish your work in this journal}

Therapeutics and Clinical Risk Management is an international, peerreviewed journal of clinical therapeutics and risk management, focusing on concise rapid reporting of clinical studies in all therapeutic areas, outcomes, safety, and programs for the effective, safe, and sustained use of medicines. This journal is indexed on PubMed Central, CAS,

\section{Dovepress}

EMBase, Scopus and the Elsevier Bibliographic databases. The manuscript management system is completely online and includes a very quick and fair peer-review system, which is all easy to use. Visit http://www.dovepress.com/testimonials.php to read real quotes from published authors.

Submit your manuscript here: http://www.dovepress.com/therapeutics-and-clinical-risk-management-journal 